\title{
Forgiveness in the treatment of alcohol and other substance abusers: a review
}

\begin{abstract}
The article provides a review of the current literature on the relationship of forgiveness and addiction. Anger, resentment, and shame seem to be the important factors of alcohol and other substance abuse, as positively associated with relapse. Despite the evidence that forgiveness can reduce feelings of anger, resentment, depression, and anxiety; as well as promote self-esteem and hope, forgiveness in addicted clients has received a little attention from empirical investigators only recently. The aim of this study is an analysis of forgiveness and associated factors within addiction. Relevant theoretical and empirical studies in this field, although most of them have cross-sectional character. Only two direct forgiveness interventions in addicted people have been conducted, but they showed a significant positive effect on the treatment of substance abusers. The article stresses forgiveness as an important factor in prevention, as well as in counselling and therapy in substance abuse clients. Forgiveness therapy by addressing anger may be particularly helpful for this population. It can be either applied independently, or combined with other psychotherapeutic approaches, so that it can have a cumulative effect on the treatment.
\end{abstract}

Keywords: addiction, alcohol, anger, forgiveness, resentment, shame, substance abuse
Volume I Issue I - 2015

\author{
Lucia Martincekova \\ Department of Psychology, University of Trnava in Trnava, \\ Slovakia
}

Correspondence: Lucia Martincekova, Department of Psychology, University of Trnava in Trnava, Slovakia, Hornopotocna 23, Trnava, 918 43, Slovakia,

Email lucia.martincekova@tvu.sk

Received: April 29, 2015 | Published: June 02, 2015

\section{Introduction}

Anger, resentment and related aggression in alcohol and other substance dependent people are significantly higher than in other

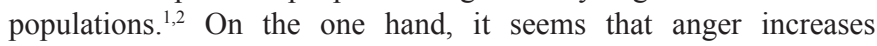
drinking. ${ }^{3,4}$ On the other hand, alcohol intoxication seems to increase the level of angry feelings, ${ }^{5}$ but the individual tend to behave aggressively under the effect of drinking when he or she is inclined to suppress the angry feelings. ${ }^{6}$ Moreover, anger was found as a common reason for relapse, especially in addicted men, ${ }^{7}$ and may be a defence mechanism against the shame associated with the addiction. ${ }^{8}$ Counsellors and therapists need to understand the factors that help clients to cope more effectively with their anger, resentment, shame, as well as whole addiction.

The importance of therapeutic working with anger and resentment was suggested previously by Alcoholic Anonymous, who mentioned resentment as the "number one offender". It seems that forgiveness may reduce feelings of anger, resentment, as well as depression and anxiety in addicted clients ${ }^{1}$ and is associated negatively with alcohol use. ${ }^{9}$ In addition, forgiveness is important, as people with drug and alcohol addiction tend to have experienced significant past hurt, trauma and posttraumatic stress disorder' symptoms. ${ }^{10,11}$

Despite the strong feelings of anger, resentment, or shame in people with addiction ${ }^{2,12}$ and the positive consequences of forgiveness to relieve these negative emotions, promote self-esteem and hope, ${ }^{1,13}$ there is a little research focus on forgiveness in alcoholics and other substance abusers. The scientific study of forgiveness in addiction and recovery has only recently begun. Intervention studies show the importance of forgiveness in addiction recovery, ${ }^{1,13}$ so that we believe that forgiveness, properly understood and done, may be beneficial for mental and psychic health of an individual. ${ }^{14}$ The purpose of the present study is, by reviewing current theoretical and empirical studies, to explore the relationships of forgiveness and addiction, with an effort to improve understanding of this area, as well as improve prevention, counselling and therapy for alcohol and other substance abuse clients.

\section{Defining forgiveness}

There is a non-existent consensus in definition of forgiveness ${ }^{15}$ that still lasts. To conceptualize the forgiveness toward others, we rely on work by Enright, ${ }^{16}$ who define forgiveness as "the overcoming of negative affect and judgment toward the offender by viewing the offender with compassion, benevolence, and love while recognizing that she/he has abandoned the right to them". We would like to mention three important components resulting from this definition. First, a person has suffered an unfair and deep hurt by the other person. Second, the person willingly chooses to forgive the other. Third, person's new stance includes affect, cognition, and behaviour. ${ }^{17,18}$ Forgiveness means giving up the negative thoughts, feelings and behaviours toward the offender, and developing positive thoughts, feelings and behaviours toward him. In some cases it is also possible to replace the original anger, resistance, desire for revenge, or indifferent behaviour with love. ${ }^{14,18-20}$

It is important to stress that forgiveness is not the same as pseudo-forgiveness, condoning, excusing, pardoning, forgetting, or denying. ${ }^{19,15}$ People sometimes do not want to forgive because they are afraid of being opened to hurt again. However, forgiveness is also not the same as reconsiling, when two people come together after separation. One may forgive but does not need to reconcise, but one never truly reconciles without forgiveness on both sides. Forgiveness, indeed, is a personal, intimate decision to give up resentment and respond with benevolence toward the offender. ${ }^{14,18}$

Enright ${ }^{17}$ introduced the forgiveness triad, which includes forgiving others, forgiving self and receiving forgiveness from others. Self-forgiveness is defined as "a willingness to abandon self- 
resentment in the face of one's own acknowledged objective wrong, while fostering compassion, generosity and love towards oneself'. ${ }^{17}$ Both forgiveness toward others and self are processes that unfold over time. They follow after a hurt, for which the offender does not deserve forgiveness but forgiveness is granted. Both of them are distinct from the other misconceptions which we mentioned above. ${ }^{17,21}$

However, there are several differences between these two types of forgiveness. First, unlike interpersonal forgiveness, self-forgiveness is always linked to reconciliation with self. Its is not possible to live separatedly of self. Second, the avoidance motivation overcome has different targets. For forgiveness toward others it concerns the victim evading the transgressor, whereas for self-forgiveness it involves motivation to avoid the victim and/or thoughts, feelings, and situations associated with the transgression. Third, forgiveness toward others is generally viewed as unconditional, while self-forgiveness may be conditional. Self-forgiveness can be linked to making continued reparative acts to the hurt part or make a commitment to never again make such an offense. ${ }^{17}$ More ever, self-forgiveness is not the same as narcissm or unnatural self-love or self-focus. Forgiveness toward self occurs withint a context of broken stadards and in a context of negative, not positive, reactions to self. ${ }^{17}$

\section{Process of forgiveness and forgiveness therapy}

Enright $^{18}$ described forgiveness as a process, not a single act. Simply saying "I forgive you" is not enough, because the angry emotions or ruminative thinking can return, so a person needs to work on forgiving. Enright ${ }^{14,20,22}$ with his colleagues described 20 steps to forgiveness in four phases. In the uncovering phase, a client needs to uncover all emotions caused by another person's injustice, such as anger and resentment. It is important to think about previously used strategies to solve the problem and to evaluate their effectiveness. After realizing the need for an alternate resolution, the decision to forgive is then introduced. Client works on reducing anger and resentment and offer benevolence toward the offender. However, it is important to understand that forgiveness is not the same as forgetting, reconciling, condoning or excusing. The work phase includes processes such as reframing by seeing the offender as a person, not because of what happened but in spite of it. Important part is working on empathy and acceptance of pain. In the discovery phase, client discovers what has been learned from the forgiveness process and from hurt experience itself. A client may find or redefine the meaning of his or her own life.

Enright \& Fitzgibbons ${ }^{19}$ model of forgiveness is focused on forgiving others, and was therapeutically used with emotionally hurt women, ${ }^{23}$ college students who experienced lack of love from a parent, ${ }^{24}$ incest survivors, ${ }^{25}$ men hurt by the abortion decision of a partner, ${ }^{26}$ participants in substance abuse treatment, ${ }^{1}$ emotionally abused women, ${ }^{27}$ and adult children of alcoholics. ${ }^{28}$ Forgiveness in therapy and education improved mental health of participants, decreased level of anger, depression, anxiety and posttraumatic stress disorder symptoms increased hope and self-esteem.

Another model focused on forgiving toward others is Worthington's ${ }^{29,30}$ psycho educational REACH model of forgiveness, which involves recalling an offense, developing empathy, choosing forgiveness as an altruistic gift, making a public, formal commitment to forgive, and holding on to progress. This model was adapted to self-forgiveness process in the study of promoting self-forgiveness in people who misuse alcohol. ${ }^{13}$

\section{Forgiveness and substance abuse}

Alcoholic anonymous says about resentment and unwillingness to forgive as barriers to recovery from addiction: “. . . obstacles (to recovery) . . . are very real. The first, and one of the most difficult, has to do with forgiveness . . . To escape looking at the wrongs we have done another, we resentfully focus on the wrongs he has done us . . Triumphantly we seize upon his misbehaviour as the perfect excuse for minimizing or forgetting our own". ${ }^{31}$ We believe that for real recovery from addiction, it is important to work on process of forgiveness toward self, as well as on forgiveness toward others.

Several studies have studied associations of guilt and shame with self-forgiveness in substance abusers. Worthington et al. ${ }^{32}$ theorized that introduction of a forgiveness component may decrease feelings of state guilt and state shame, and thereby reduce probability of relapse, as well as engaging in alcohol use as a coping mechanism. This is an important statement, as the relationship between shame and substance abuse seems to be cyclical - substance abuse leads to shame and shame leads to substance abuse. ${ }^{33}$

Lewis ${ }^{8}$ stated that anger may work as a defence mechanism against the shame associated with the addiction. Similarly, addiction may work as a defence mechanism against feelings of shame. Especially shameprone individuals may discover that alcohol, substance abuse, or other compulsive behaviours help them feel less shameful. ${ }^{12}$ However, it is important to understand that this effect may last only for a short period of time and addiction can then only lead to a greater shame.

Gueta $^{34}$ conducted qualitative study of self-forgiveness in the recovery of Israeli drug-addicted mothers. The main difference between the participants who forgave themselves and those who did not was associated with their feeling of shame. The participants who forgave themselves for addiction refused to see their behaviour as a reflection of their self-worth. That means that they can distinguish their behaviour and their personality, and were thus released from painful shame. Self-forgiveness was also found to be associated with reduction of guilt feelings. On the other hand, participants who did not forgive themselves felt great feelings of shame, and they described their identities with self-loathing and dehumanization. Also, similar finding can be seen in McGaffin et al..$^{35}$ study. Authors found that guilt had a positive association with self-forgiveness, whereas shame was negatively associated with self-forgiveness. This brings us to the question - Where leads the important difference between guilt which can facilitate self-forgiveness, and between shame, which can be a barrier to self-forgiveness?

The first important distinction between guilt and shame was done by Lewis ${ }^{8}$ and was scientifically proved many times to date. Guilt and shame are common, painful intropunitive emotions focused either on behaviour ("I did something wrong" in the case of guilt) or on character ("I'm wrong" in the case of shame) ${ }^{8}$ It is important to educate clients about the differences between guilt and shame, so that they can concentrate on their behaviour itself (feelings of guilt) with repairing their past offences, on making amends, apologizing and seeking forgiveness from others. When they try to seek forgiveness from others (in case it is not more hurtful for others) they can also learn about the importance of forgiveness, and may feel the need to forgive others.

Moreover, when testing the possible mediators (acceptance, conciliatory behaviour and empathy) of the relationships between 
shame and guilt with self-forgiveness in substance abusers, it was found that acceptance mediated the guilt and self-forgiveness relationship and had an indirect effect on the shame and selfforgiveness relationship. These findings emphasize the importance of targeting acceptance when trying to reduce the effects of shame and guilt on self-forgiveness in alcohol and other substance abusers. ${ }^{35}$

\section{Health related concerns with forgiveness and substance abuse}

On a theoretical level, it has been stated that self- forgiveness would be associated with improved health status, as well as reduced problematic drinking. ${ }^{32}$ Supporting this expectation, some recent series of studies approved this theoretical assumption.

Study conducted by Webb \& Brewer ${ }^{36}$ showed a negative association between forgiveness and alcohol use, as well as a negative association between forgiveness and mental health symptomatology in alcohol dependent clients. The study showed that feeling for being forgiven by God is probably easier for participants than forgiveness toward others. The authors provided the preliminary evidence that forgiveness toward self can be the most difficult for alcohol dependent, as it was found as the lowest from all types of forgiveness in participants. However, we see as the biggest limitation of the study methodology using only three single items for assessing different types of forgiveness.

Webb \& Brewer ${ }^{36}$ examined college student problematic drinkers and found an association between forgiveness and health among those individuals who may be experiencing health-related problems. Authors again found out that self-forgiveness appears to be the most important dimension of forgiveness triad associated with health, as well as the most difficult to develop.

In other cross-sectional studies, there have been found some factors associated with relapse. Willinger et al. ${ }^{37}$ found that high level of trait anxiety, and personality traits such as high novelty seeking and low harm avoidance covering exploratory excitability, impulsiveness, extravagance, disorderliness and uninhibited optimism, predicted returning to uncontrolled drinking.

\section{Forgiveness therapy within addiction}

Despite the first important attempts of studies on forgiveness and addiction, their cross-sectional nature allow us only to theorize that forgiveness may lessen alcohol and other substance abuse, as well as to promote health effects associated with alcohol use. To date, we know only about two interventions in this area, which directly applied forgiveness toward others or forgiveness toward self in substance abuse clients.

First intervention was focused on forgiveness toward others. Lin et al. ${ }^{1}$ provided forgiveness therapy in inpatient-substance dependent patients, using Enright's 20 step model, ${ }^{20,22}$ individually provided in 12 twice-weekly sessions. Participants receiving forgiveness therapy, showed significant improvement in total and trait anger, depression, total and trait anxiety, self-esteem, forgiveness, and vulnerability to drug use, compared to participants in alternative treatment group.

Another research based intervention was done in dissertation thesis by Scherer et al., ${ }^{13}$ who conducted first self-forgiveness intervention in this area, within a community sample undergoing treatment for alcohol abuse. Participants in the treatment condition completed a four-hour self-forgiveness intervention, divided into three 90 minute sessions over three consecutive weeks, using "Forgiveness and the Bottle: A workshop to promote self-forgiveness in individuals dealing with alcohol and drug abuse Participant Manual", the manual created by the author, using Worthington's REACH model. ${ }^{29,30}$ Participants' level of self-forgiveness was significantly higher as in the waiting list control group, as well as their drinking refusal self-efficacy was improved. After receiving forgiveness intervention, participants were specifically able to forgive themselves for their alcohol-related transgressions, and thereby reduce the feelings of shame and guilt resulted from such offenses.

These studies provided the first evidence that forgiveness can lead to recovery from addiction. Forgiveness interventions helped participants to improve their forgiveness, health status and coping associated with their problematic drinking. We believe that using forgiveness intervention and therapy can be effective in reduction of problematic factors, such as anger, anxiety, depression and strengthening self-esteem and hope, and thereby in protecting of relapse. However, there is a strong need for other research-based forgiveness interventions in this area and longitudinal study of these relationships.

\section{Forgiveness therapy and other treatments for addiction}

We can see important similarities between techniques and processes used in forgiveness therapy by Enright \& Fitzgibbons ${ }^{19}$ and in the 12-steps program of AA. ${ }^{34}$ Step 4 in AA encourages clients to make a moral inventory of self, while step 5 encourage admitting to God, to self and the other person exact offenses which person has done. Similarity can be seen in uncovering phase of forgiveness, where is important to identify wrongs, hurt actions from the past, and feelings of anger and resentment.

Step 8 of AA recommends person to make a list of all persons which he or she had hurt in the past and if possible, to try to make amends to them. Also, in AA program we can see encouraging clients to associate a need to be forgiven by others with possibility to forgive others: "If we are now about to ask forgiveness for ourselves, why shouldn't we start by forgiving them, one and all?". ${ }^{31}$ In forgiveness therapy ${ }_{1}^{18}$ it is also important to identify people who hurt in the past, and similar can be stated for self-forgiveness, to make a list of people who client have hurt.

Step 9 encourages alcoholics to reconstruct on broken relationships, to make steps to reconcile if possible. In step 10, there is an emphasis on continuing self-monitoring, growth, apologizing and forgiveness toward self: "we continue to take personal inventory and when we were wrong promptly admitted it". ${ }^{31}$

Forgiveness intervention can be provided either alone or incorporated to other types of therapy. We agree with the statement of Webb et $a .^{38}$ that incorporating forgiveness into the otherwise traditional psychological practice(s) of psychotherapy may have a cumulative effect- greater than the effect of either alone. There are several psychotherapeutic approaches already used within addiction, where forgiveness can be incorporated, such as TwelveStep Facilitation Therapy, ${ }^{39}$ Acceptance and Commitment Therapy, ${ }^{40}$ Dialectical Behaviour Therapy, ${ }^{41}$ and Mindfulness based Cognitive Therapy. ${ }^{42}$ 


\section{Substance abuse as a problem of the family system and forgiveness}

When we think about alcohol abuse as affecting all the family system, we can notice that not only abusers may have problems with forgiveness. For other family members suffering from dependence and related problematic behaviour of their relatives can be very difficult, or even impossible to forgive. Vulnerable group can be especially children who grow up with at least one alcoholic parent. As research suggests, despite individual differences, adult children of alcoholics generally tend to experience higher levels of distress, anger, anxiety, more depressive symptoms, greater adjustment difficulties, and have fewer and less effective coping strategies. ${ }^{43-45}$

We found only one forgiveness research based intervention used in adult children of alcoholics. Osterndorf et al. ${ }^{46}$ conducted the pilot study which tested the effects of forgiveness therapy in adult children of alcoholics. Authors found that forgiveness therapy decreased levels of depression, anger and anxiety, improved self-esteem and quality of interpersonal relationships in participants.

Again, there is a need for another research-based intervention for other family members of substance abusers. We believe, when working with family system, promoting forgiveness may be beneficial for the entire family. Not only for clients in rehabilitation as a treatment and prevention of relapse, but also for other family members as a way to heal wounds of the past and for overall strengthening relationships in the family.

\section{Conclusion}

As Alcoholic Anonymous stated, resentment is the "number one' offender" for addicted clients. Anger and resentment may promote addiction, ${ }^{3}$ and addiction may promote anger and resentment. ${ }^{5}$ In addition, anger may be used as a defence mechanism against the shame associated with the addiction. ${ }^{8}$ One way to reduce feelings of anger, resentment, and shame is through forgiveness.

For substance abusers, both self-forgiveness and forgiveness toward others may be relevant. Very often addicted clients suffer from offences, pain and posttraumatic symptoms from the past. ${ }^{10} \mathrm{We}$ believe that by forgiving to the person who has hurt them in the past, their level of anger and resentment, as well as their addiction may be reduced.

As part of the forgiveness triad, ${ }^{17}$ self-forgiveness seems to be the most difficult type of forgiveness to develop in addicted people, compared with forgiveness toward others and feelings of forgiveness by God. ${ }^{9}$ Research shows different relationship of forgiveness with shame and guilt, where guilt is associated positively with selfforgiveness, while shame is negatively. ${ }^{35}$ It is important to educate clients about differences between guilt and shame, ${ }^{8}$ so that they can concentrate on their bad behaviour and try to repair it (in case of guilt), instead of over-concentrating on their bad self (in case of shame). It is also important to work therapeutically on shame, ${ }^{12}$ especially though acceptance. ${ }^{25}$ To date, only two direct forgiveness interventions in addicted people have been conducted. First, by using Enright and Fitzgibbons' 20 step model of forgiving others, ${ }^{1}$ showed positive effect in decreasing levels of total and trait anger, depression, anxiety, improved vulnerability to drug use, as well as promoted forgiveness and self-esteem in participants. Second, using Worthington' REACH model $^{13}$ of self-forgiveness and forgiveness toward others, showed positive effect in promoting self-forgiveness and drinking refusal self- efficacy in participants, as well as in decreasing levels of shame and guilt. These interventions illustrated a positive effect of both types of forgiveness, toward others and toward self, on treatment of addiction and psychic health of participants. Other interventions in this area are needed to support these results.

We believe that the full recovery from substance abuse cannot be reached without fully forgiving of self and others. Forgiveness, by reducing levels of anger, resentment, depression, and anxiety, may prevent relapse, promote acceptation of self and strengthen relationships with others. There have been found similarities between techniques and processes used in forgiveness therapy by Enright and Fitzgibbons, ${ }^{19}$ and in the 12-steps program of Alcoholic Anonymous. ${ }^{31}$ It seems that forgiveness may be promoted independently, or combined with other psychotherapeutic approaches, such as TwelveStep Facilitation Therapy, ${ }^{39}$ Acceptance and Commitment Therapy, ${ }^{40}$ Dialectical Behaviour Therapy, ${ }^{41}$ and Mindfulness based Cognitive Therapy. ${ }^{42}$

Knowledge of the relationship of forgiveness and addiction, and specific features of anger, resentment, shame and guilt may be used in treatment and prevention planning. We see a strong need of another forgiveness research based intervention in this area. It could be valuable to promote forgiveness toward others and self-forgiveness at the same time, as they both seems to be relevant and beneficial within addiction. More research studies should concentrate on relationship between forgiveness and addiction.

"Resentment is the 'number one' offender. It destroys more alcoholics than anything else."

- Alcoholics Anonymous (2001, p. 64)

\section{Acknowledgements}

None.

\section{Conflict of interest}

The author declares no conflict of interest.

\section{References}

1. Lin WF, Mack D, Enright RD, et al. Effects of forgiveness therapy on anger, mood, and vulnerability to substance use among inpatient substance-dependent clients. J Consult Clin Psychol. 2004;72(6):114 121.

2. Ilyuk RD, Gromyco DI, Kiselev AS, et al. Hostility and anger in patient dependent on different psychoactive drugs. Activitas Nervosa Superior. 2012;54(3-4):125-134

3. Morrison PM, Noel NE, Ogle RL. Do angry women choose alcohol? Addict Behav. 2012;37(8):908-913.

4. Foran HM, O'Leary KD. Problem Drinking, Jealousy, and Anger Control: Variables Predicting Physical Aggression Against a Partner. Journal of Family Violence. 2008;23(3):141-148.

5. Zeichner A, Allen JD, Giancola PR, et al. Alcohol and aggression: effects of personal threat on human aggression and affective arousal. Alcohol Clin Exp Res. 1994;18(3):657-663.

6. Norström T, Pape H. Alcohol, suppressed anger and violence. Addiction. 2010;105(9):1580-1586.

7. Levy MS. Listening to our clients: the prevention of relapse. $J$ Psychoactive Drugs. 2008;40(2):167-172. 
8. Lewis H. Shame and guilt in neurosis. New York: International Universities Press; 1971. 525 p.

9. Webb JR, Robinson EA, Brower KJ, et al. Forgiveness and alcohol problems among people entering substance abuse treatment. J Addict Dis. 2006;25(3):55-67.

10. Stevens S, Murphy BS, McKnight K. Traumatic stress and gender differences in relationship to substance abuse, mental health, physical health, and HIV risk behaviour in a sample of adolescents enrolled in drug treatment. Child Maltreat. 2003;8(1):46-57.

11. Langman L, Chung MC. The relationship between forgiveness, spirituality, traumatic guilt and posttraumatic stress disorder (PTSD) among people with addiction. Psychiatr Q. 2013;84(1):11-26.

12. Potter-Efron RT. Therapy with shame-prone alcoholic and drug dependent clients. In: Dearing RL \& Tangney JP, Editors. Shame in the Therapy hour. 2nd ed. Washington DC, USA: American Psychological Assosication; 2011. p. 219-235.

13. Scherer M, Worthington EL, Hook JN, et al. Forgiveness and the bottle: promoting self-forgiveness in individuals who abuse alcohol. J Addict Dis. 2011;30(4):382-395.

14. Enright RD. The Forgiving Life: A Pathway to Overcoming Resentment and Creating a Legacy of Love. Washington, DC, USA: American Psychological Association; 2012. 384 p.

15. McCullough ME, Pargamen KI, Thoresen CE. Forgiveness: Theory, Research and Practice. New York: The Guilford Press; 2001. 334 p.

16. Enright RD. The moral development of forgiveness. In: Puka B, editor. Reaching out: Caring, altruism, and prosocial behavior. Routledge, Garland, New York, USA; 1994. p. 219-248.

17. Enright RD. Counseling Within the Forgiveness Triad: On Forgiving, Receiving Forgiveness, and Self-Forgiveness. Counseling and Values. 1996;40(2):107-126.

18. Enright RD. Forgiveness is a Choice. A Step-by- step process for resolving anger and restoring hope. American Psychological Association. Washington DC, USA, 2001. 299 p.

19. Enright RD, Fitzgibbons RP. Helping clients forgive: An empirical guide for resolving anger and restoring hope. American Psychological Association. Washington DC, USA, 2000.376 p.

20. Enright RD, Freedman S, Rique J. The psychology of interpersonal forgiveness. In: Enright RD, North J, Tutu AD, Editors. Exploring forgiveness. Wisconsin, USA: University of Wisconsin Press; 1998. $46-62$.

21. Hall JH, Fincham FD. Self-forgiveness: the stepchild of forgiveness research. Journal of Social and Clinical Psychology. 2005;24(5):621637

22. Enright RD, Fitzgibbons RP. Forgiveness therapy: an empirical guide for resolving anger and restoring hope. Washington, DC, USA: American Psychological Association; 2014. 358 p.

23. Hebl JH, Enright RD. Forgiveness as a psychotherapeutic goal with elderly females. Psychotherapy \& Psychosomatics. 1993;30(4):658-667.

24. Al-Mabuk A, Enright RD, Cardis PA. Forgiveness Education with Parentally Love-deprived Late Adolescents. Journal of Moral Education. $1995 ; 24(4): 427-444$

25. Freedman SR, Enright RD. Forgiveness as an intervention goal with incest survivors. J Consult Clin Psychol. 1996;64(5):983-992.

26. Coyle CT, Enright RD. Forgiveness intervention with postabortion men. J Consult Clin Psychol. 1997;65(6):1042-1046.
27. Reed GL, Enright RD. The effects of forgiveness therapy on depression, anxiety, and posttraumatic stress for women after spousal emotional abuse. J Consult Clin Psychol. 2006;74(5):920-929.

28. Osterndorf CL, Enright RD, Holter AC, et al. Treating Adult Children of Alcoholics Through Forgiveness Therapy. Alcoholism Treatment Quarterly. 2011;29(3):274-292.

29. Worthington EL. Forgiveness and reconciliation: Theory and Application. Brunner-Routledge, New York, USA, 2006. 328 p.

30. Worthington EL. Forgiveness intervention manuals. 2006

31. Twelve Steps and Twelve Traditions. Alcoholics Anonymous Inc. New York, USA, 1981. 358 p.

32. Worthington JEL, Scherer M, Cooke KL. Forgiveness in the Treatment of Persons with Alcohol Problems. Alcoholism Treatment Quarterly. 2006;24(1-2):125-145.

33. Dearing RL, Stuewig J, Tangney JP. On the importance of distinguishing shame from guilt: Relations to problematic alcohol and drug use. Addict Behav. 2005;30(7):1392-1404.

34. Gueta K. Self-Forgiveness in the Recovery of Israeli Drug-Addicted Mothers: A Qualitative Exploration. Journal of Drug Issues. 2013;43:450-467.

35. McGaffin BJ, Lyons GC, Deane FP. Self-Forgiveness, shame, and guilt in recovery from drug and alcohol problems. Subst Abus. 2013;34(4):396404

36. Webb JR, Brewer K. Forgiveness, health, and problematic drinking among college students in southern Appalachia. J Health Psychol. 2010;15(8):1257-1266

37. Willinger U, Lenzinger E, Hornik K, et al. Anxiety as a predictor of relapse in detoxified alcohol-dependent patients. Alcohol Alcohol. 2002;37(6):609-612.

38. Webb JR, Toussaint L, Conway-Williams E. Forgiveness and health: psycho-spiritual integration and the promotion of better healthcare. $J$ Health Care Chaplain. 2012;18(1-2):57-73.

39. Nowinski J. Facilitating 12-Step recovery from substance abuse. In Walters ST \& Rotgers F, editors. Treating substance abuse: Theory and technique. 3rd ed. New York: Guilford Press; 2012. p. 191-223.

40. Hayes SC, Lillis J. Acceptance and Commitment Therapy. Washington DC, USA: American Psychological Association; 2012. 168 p.

41. Neacsiu AD, Ward-Ciesielski EF, Linehan MM. Emerging Approaches to Counseling Intervention: Dialectical Behavior Therapy. The Counseling Psychologist. 2012;40:1003-1032.

42. Felder JN, Dimidjian S, Segal Z. Collaboration in Mindfulness-Based Cognitive therapy. J Clin Psychol. 2012;68(2):179-186.

43. Hall CW, Webster RE. Multiple stressors and adjustment among adult children of alcoholics. Addiction Research \& Theory. 2007;15(4):425434.

44. Klostermann K, Chen R, Kelley ML, et al. Coping behavior and depressive symptoms in adult children of alcoholics. Subst Use Misuse. 2011;46(9):1162-1168.

45. Watt TT. Marital and cohabiting relationships of adult children of alcoholics: Evidence from the National Survey of Family Households. Journal of Family Issues. 2002;23(2):246-265.

46. Osterndorf CL, Enright RD, Holter AC, et al. Treating adult children of alcoholics through forgiveness therapy. Alcoholism Treatment Quarterly. 2011;29(3):274-292. 